\title{
Modulation of Long-Term Depression by Dopamine in the Mesolimbic System
}

\author{
Mark J. Thomas, ${ }^{1}$ Robert C. Malenka, ${ }^{1}$ and Antonello Bonci ${ }^{2}$ \\ ${ }^{1}$ Nancy Pritzker Laboratory, Department of Psychiatry and Behavioral Sciences, Stanford University School of Medicine, \\ Palo Alto, California 94134, and 2Ernest Gallo Clinic and Research Center and Department of Neurology, University of \\ California, San Francisco, San Francisco, California 94110
}

\begin{abstract}
Long-lasting adaptations in the mesolimbic dopamine (DA) system in response to drugs of abuse likely mediate many of the behavioral changes that underlie addiction. Recent work suggests that long-term changes in synaptic strength at excitatory synapses in the two major components of this system, the nucleus accumbens (NAc) and ventral tegmental area, may be particularly important for the development of drug-induced sensitization, a process that may contribute to addiction, as well as for normal response-reinforcement learning. Using whole-cell patch-clamp recording techniques from in vitro slice preparations, we have examined the existence and basic mechanisms of long-term depression (LTD) at excitatory synapses on both
\end{abstract}

GABAergic medium spiny neurons in the NAc and dopaminergic neurons in the midbrain. We find that both sets of synapses express LTD but that their basic triggering mechanisms differ. Furthermore, DA blocks the induction of LTD in the midbrain via activation of D2-like receptors but has minimal effects on LTD in the NAc. The existence of LTD in mesolimbic structures and its modulation by DA represent mechanisms that may contribute to the modifications of neural circuitry that mediate reward-related learning as well as the development of addiction.

Key words: long-term depression; ventral tegmental area; nucleus accumbens; dopamine; addiction; synaptic plasticity; mesolimbic; learning
A major component of the neural circuit that is thought to mediate "incentive motivation" and "reinforcement" is the mesolimbic dopamine (DA) system, which consists of the ventral tegmental area (VTA) and the nucleus accumbens (NAc) along with their afferent and efferent connections (Robbins and Everitt, 1996). The clinical importance of developing a sophisticated understanding of this brain system at all levels from the molecular to the behavioral has been repeatedly emphasized because of its postulated importance in mediating many of the behavioral and/or psychological actions of drugs of abuse as well as its potential role in major mental illnesses such as schizophrenia. Although much is known about the anatomy of the NAc and VTA and some of the cellular and molecular changes that occur within these structures after exposure to therapeutic drugs and drugs of abuse, surprisingly little is known about the basic properties of excitatory synapses in these regions.

Recently, we have begun to examine the properties of excitatory synapses in the NAc and VTA and their modulation by neurotransmitters and psychostimulant drugs of abuse (Nicola et al., 1996; Nicola and Malenka, 1997, 1998; Bonci and Malenka, 1999). In addition, we and others have demonstrated that both sets of synapses express an NMDA receptor-dependent form of long-term potentiation (LTP) (Pennartz et al., 1993; Kombian and Malenka, 1994; Bonci and Malenka, 1999; Overton et al., 1999). That plasticity at excitatory synapses in the NAc and VTA may be functionally important is supported by behavioral studies of responsereinforcement learning (Kelley et al., 1997) and analysis of the behavioral sensitization that develops in response to psychomotor stimulants (Clark and Overton, 1998; Wolf, 1998). This behavioral sensitization was originally considered a model for the develop-

Received Jan. 14, 2000; revised May 1, 2000; accepted May 5, 2000.

This work was supported by grants from the National Institute on Drug Abuse (NIDA), the National Institute of Mental Health, and the McKnight Endowment Fund for Neuroscience to R.C.M. M.J.T. was supported by a National Research Service Award from NIDA. A.B. was supported by funds provided by the State of California for medical research on alcohol and substance abuse through the University of California, San Francisco, and Fondazione Cassa di Risparmio di Rimini. We thank Julie Kauer for sharing her laboratory's results before publication.

Correspondence should be addressed to Dr. Antonello Bonci, Gallo Clinic and Research Center, 5858 Horton Street, Suite 200, Emeryville, CA 94608. E-mail: bonci@itsa.ucsf.edu.

Copyright (C) 2000 Society for Neuroscience $0270-6474 / 00 / 205581-06 \$ 15.00 / 0$ ment of psychosis (Segal and Schuckit, 1983; Robinson and Becker, 1986) and more recently has been considered a model for the intensification of drug craving that occurs in humans and that likely contributes to relapse (Kalivas and Stewart, 1991; Robinson and Berridge, 1993).

Although LTP has been observed in both the NAc (Pennartz et al., 1993; Kombian and Malenka, 1994) and VTA (Bonci and Malenka, 1999; Overton et al., 1999), whether long-term depression (LTD) can be reliably elicited in these structures is not known, and therefore we focused on this form of synaptic plasticity. In the hippocampus and cortex, the demonstration that both LTD and LTP exist was important because it demonstrated that activity can bidirectionally control synaptic strength (Bear and Abraham, 1996). This bidirectional control of synaptic strength greatly increases the flexibility and storage capacity of neural circuits (Sejnowski, 1977) and also may play a key role in the experiencedependent modification of neural circuitry during development (Singer, 1995; Katz and Shatz, 1996). Indeed, a priori, there is no reason to assume that LTP is a more useful mechanism than LTD for information storage or the experience-dependent modification of neural circuitry (Bear, 1999). Here, we demonstrate that LTD can be elicited at excitatory synapses in both the NAc and VTA but that the two forms of LTD are triggered by distinct mechanisms and are differentially modulated by DA.

\section{MATERIALS AND METHODS}

Slice preparations. Sagittal slices of the NAc and horizontal slices of the midbrain containing the VTA and pars compacta of the substantia nigra $(\mathrm{SNc})$ were prepared as described previously (Nicola et al., 1996; Bonci and Malenka, 1999). C57/BL6 (28-60 d; NAc experiments) or DBA-2J (21-35 $\mathrm{d}$; VTA and SNc experiments) mice were anesthetized with halothane before killing, and appropriate blocks of tissue were sliced in the horizontal $(190-250 \mu \mathrm{m})$ or sagittal $(250 \mu \mathrm{m})$ planes with a vibratome (Leica, Nussloch, Germany). Slices (two per animal for the VTA; two to four per animal for the NAc) were placed in a holding chamber and allowed to recover for at least $1 \mathrm{hr}$ before being placed in the recording chamber and superfused with a bicarbonate-buffered solution saturated with $95 \%$ $\mathrm{O}_{2} / 5 \% \mathrm{CO}_{2}$ and containing (in $\mathrm{mM}$ ): $126 \mathrm{NaCl}, 1.6 \mathrm{KCl}, 1.2 \mathrm{NaH}_{2} \mathrm{PO}_{4}, 1.2$ $\mathrm{MgCl}_{2}, 2.5^{\mathrm{CaCl}_{2}}, 18 \mathrm{NaHCO}_{3}$, and 11 glucose (at $32-34^{\circ} \mathrm{C}$ for VTA and $\mathrm{SNc}$ experiments); or $119 \mathrm{NaCl}, 2.5 \mathrm{KCl}, 1.0 \mathrm{NaH}_{2} \mathrm{PO}_{4}, 1.3 \mathrm{MgCl}_{2}, 2.5$ $\mathrm{CaCl}_{2}, 26.2 \mathrm{NaHCO}_{3}$, and 11 glucose (at $27-29^{\circ} \mathrm{C}$ for NAc experiments). Picrotoxin $(100 \mu \mathrm{M})$ was also added to these solutions to block $\mathrm{GABA}_{\mathrm{A}}$ receptor-mediated IPSCs. 
Whole-cell recording. Cells were visualized with an upright microscope (Olympus) using infrared-differential interference contrast video microscopy. Whole-cell voltage-clamp recordings were made using an Axopatch 1D amplifier (Axon Instruments, Foster City, CA). Patch electrodes (3-8 $\mathrm{M} \Omega$ ) contained (in mM): 117 cesium gluconate, $2.8 \mathrm{NaCl}, 20 \mathrm{HEPES}, 0.4$ EGTA, 5 TEA-Cl, 2.5 MgATP, and 0.25 MgGTP, pH 7.2-7.4 (285-295 mOsm). When 1,2-bis(2-aminophenoxy)ethane- $N, N, N^{\prime}, N^{\prime}$-tetra-acetic acid (tetracesium salt; BAPTA; $10 \mathrm{~mm}$; Molecular Probes, Eugene, OR) was added to the solution, cesium gluconate was adjusted to $117 \mathrm{~mm}$. Experiments were begun only after series resistance had stabilized (typically 10-40 M $\Omega$ ). Series resistance and input resistance were monitored continuously on-line with a $4 \mathrm{mV}$ depolarizing or hyperpolarizing step (25-70 msec), which was given with every afferent stimulus. For the NAc experiments, medium spiny neurons were identified by their morphology and high resting membrane potential $(-75$ to $-85 \mathrm{mV})$. Stainless steel bipolar microelectrodes were placed at the prelimbic cortex-NAc border to stimulate afferents preferentially from the prelimbic cortex. Data collected from cells in both the shell and core of the NAc were combined because no differences were observed. For VTA and SNc experiments, DA cells were identified by the presence of a large $I_{h}$ current (Johnson and North, 1992) that was assayed immediately after break-in, using a series of incrementa $10 \mathrm{mV}$ hyperpolarizing steps from a holding potential of $-70 \mathrm{mV}$. A bipolar stainless steel stimulating electrode was placed 100-300 $\mu \mathrm{m}$ rostral to the recording electrode. In both preparations, excitatory afferents were stimulated at a baseline frequency of $0.1 \mathrm{~Hz}$. Neurons were voltageclamped at a membrane potential of -70 to $-80 \mathrm{mV}$ except where noted.

Data were filtered at $2 \mathrm{kHz}$, digitized at $5-10 \mathrm{kHz}$, and collected on-line using custom software (IgorPro; Wavemetrics, Lake Oswego, OR). The amplitudes of EPSCs were calculated by taking the mean of a 2-4 msec window around the peak and comparing this with the mean of a $2-8 \mathrm{msec}$ window immediately before the stimulation artifact. The magnitude of LTD was measured by comparing the mean EPSC amplitude during the final 30 sweeps of the baseline period with the mean EPSC amplitude during 30 consecutive sweeps taken 25-30 (NAc) or 15-20 (VTA) minutes after the pairing procedure. Results in the text and figures are presented as the mean \pm SEM.

Drugs were added to the superfusing medium at known concentrations immediately before application to the slice. D-2-Amino-5-phosphonovaleric acid (D-APV), $N$-(4-hydroxyphenylpropanoyl)-spermine (NHPP-SP), $(S)$ methyl-3-carboxy-4-hydroxyphenylglycine [( $S)$-MCPG], $(R S)$ - $\alpha$-cyclopropyl4-phosphonophenylglycine (CPPG), and 2-methyl-6-(phenylethynyl)pyridine (MPEP) were obtained from Tocris (Ballwin, MO). Picrotoxin and dopamine were obtained from Sigma (St. Louis, MO). Nifedipine, methiothepin, SCH-23390, SKF 81297, sulpiride, eticlopride, and haloperidol were obtained from Research Biochemicals (Natick, MA).

\section{RESULTS}

\section{LTD in medium spiny neurons in the nucleus accumbens}

In the first set of experiments, EPSCs were recorded from medium spiny neurons in sagittal slices of the NAc using whole-cell patchclamp recording techniques. As shown in Figure 1, $a$ and $b$, LTD could be reliably induced by applying $1 \mathrm{~Hz}$ stimulation while holding the cell at $-50 \mathrm{mV}$. LTD always lasted for the duration of the recording (30-60 min after the induction protocol; $n=15$; $72 \pm 5 \%$ of baseline) and was not associated with any significant change in input or series resistance.

To test whether, like LTP (Pennartz et al., 1993; Kombian and Malenka, 1994), the triggering of LTD in the NAc was dependent on the activation of NMDA receptors (NMDARs), we applied D-APV $(50 \mu \mathrm{M})$ during the induction protocol. On average, this greatly reduced or blocked LTD (Fig. $1 c ; n=9 ; 94 \pm 8 \%$ of baseline). In some of these cells, we washed out the D-APV and reapplied the induction protocol that now elicited LTD $(n=4$; $82 \pm 2 \%$ of baseline). We also recorded from cells using a pipette solution containing the calcium chelator BAPTA $(10 \mathrm{~mm})$, and as expected, this prevented the generation of LTD $(n=4 ; 98 \pm 9 \%$ of baseline; data not shown). These results demonstrate that, like the LTD observed in some other brain regions, NMDAR activation and the consequent change in postsynaptic calcium concentration are required for the triggering of LTD in the NAc.

In the dorsal striatum (Calabresi et al., 1992) as well as in the hippocampus (Oliet et al., 1997), there are forms of LTD that require activation of metabotropic glutamate receptors (mGluRs). To test whether mGluRs play an important role in triggering LTD in the NAc, we applied the mGluR antagonist $(S)$-MCPG at a concentration $(1.5 \mathrm{~mm})$ that blocked mGluR-dependent LTD in the hippocampus (Oliet et al., 1997). This manipulation had no significant effect on LTD in the NAc $(n=6 ; 78 \pm 6 \%$ of baseline;
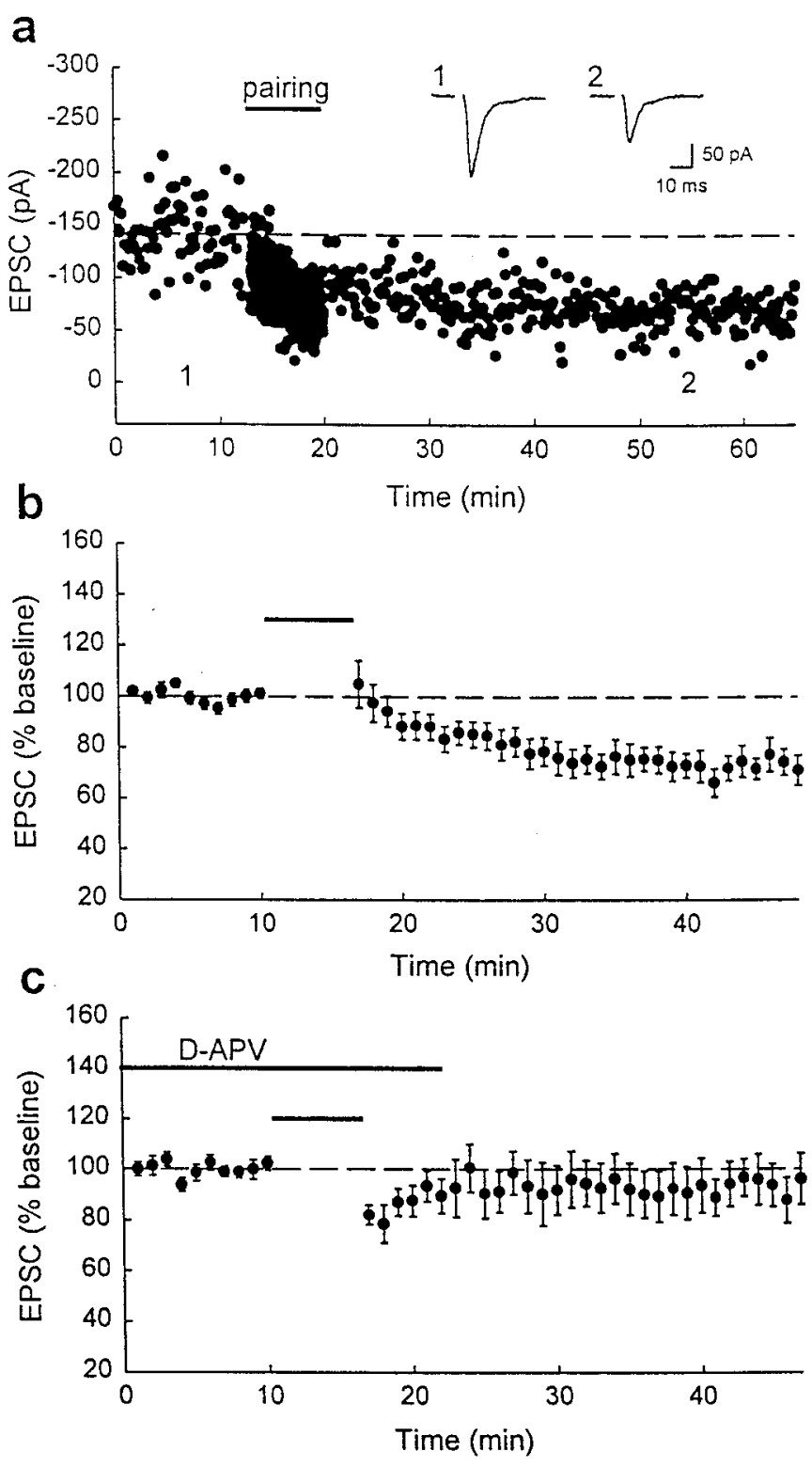

Figure 1. LTD can be elicited in the NAc and requires activation of NMDA receptors. $a$, Typical example of LTD induced by applying $1 \mathrm{~Hz}$ afferent stimulation while holding the cell at $-50 \mathrm{mV}$ ( pairing; indicated by the short horizontal bar in this and all subsequent figures). Insets, EPSCs $(n=6)$ collected at the times indicated by the numbers $(1,2)$ on the graph. $b$, Summary graph of the average LTD elicited in 15 NAc cells. $c$, Summary graph showing the effects of applying D-APV $(50 \mu \mathrm{M})$ during the pairing protocol $(n=9)$.

data not shown). Because it has been reported that MCPG does not block the stimulation of phosphoinositide hydrolysis elicited by glutamate acting on mGluR5 receptors (Brabet et al., 1995; Huber et al., 1998), we performed additional experiments in which we applied $(S)$-MCPG along with the noncompetitive mGluR5 antagonist MPEP $(20 \mu \mathrm{M})$ as well as the group II/III antagonist CPPG $(200 \mu \mathrm{M})$ (Schoepp et al., 1999). In this cocktail of mGluR antagonists, we were still able to elicit LTD $(n=4 ; 83 \pm 6 \%$ of baseline $)$. Thus we conclude that activation of mGluRs is not required to elicit this form of LTD in the NAc.

LTD in the dorsal striatum also appears to require simultaneous activation of D1-like and D2-like DA receptors (Calabresi et al., 1992). To test whether there is a similar requirement for LTD in the NAc, we applied the D1 receptor antagonist SCH-23390 (20 $\mu \mathrm{M})$ and the D2 receptor antagonists sulpiride $(10 \mu \mathrm{M})$ or haloperidol $(2 \mu \mathrm{M})$ and found that these drugs had no effect on the triggering of LTD (Fig. $2 a ; n=6 ; 60 \pm 4 \%$ of baseline). Finally, we 
a
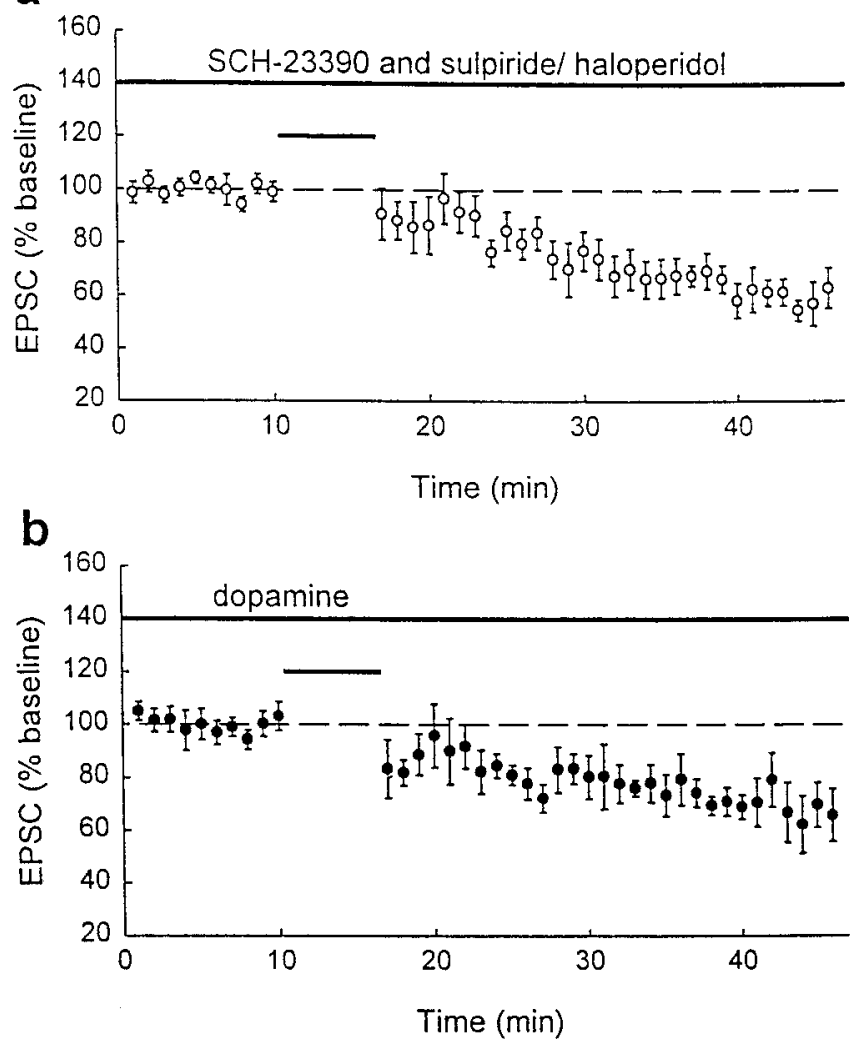

Figure 2. LTD in the NAc is not affected by DA receptor antagonists or DA. $a$, Summary graph showing the lack of effect of D1-like (SCH-23390; $20 \mu \mathrm{M}$ ) and D2-like (sulpiride, $10 \mu \mathrm{M}$, or haloperidol, $2 \mu \mathrm{M}$ ) receptor antagonists on LTD $(n=6) . b$, Summary graph showing that DA $(75 \mu \mathrm{M})$ does not block LTD $(n=6)$. Baseline was obtained after DA had been applied for 15-20 min to allow its depressant effect on synaptic transmission to stabilize.

also examined whether DA itself might modulate LTD. In agreement with previous results (Nicola et al., 1996; Nicola and Malenka, 1997, 1998), DA $(75 \mu \mathrm{M})$ caused a decrease in basal synaptic transmission ( $n=6 ; 66 \pm 5 \%$ of baseline) but had no significant effect on the ability to generate LTD that was induced after the DA-induced decrease in synaptic strength had stabilized (Fig. $2 b$; $75 \pm 10 \%$ of baseline). Thus LTD in the NAc requires NMDAR activation but not mGluR or DA receptor activation and is not modulated by DA. These results represent further examples of how DA functions differently in modulating excitatory synaptic transmission in the dorsal versus ventral regions of the striatum (Nicola and Malenka, 1998).

\section{LTD in midbrain dopamine cells}

In a second series of experiments, we examined whether a similar induction protocol could elicit LTD in the DA cells of the VTA and SNc in horizontal slices of the midbrain. This is of particular interest because both of these cell groups play an important role in the prediction of reward during learning (Schultz et al., 1997; Schultz, 1998) and synaptic plasticity at the excitatory synapses formed by prefrontal cortical afferents on midbrain DA cells has been suggested to be a key trigger for psychostimulant-induced behavioral sensitization (Clark and Overton, 1998; Wolf, 1998; Cador et al., 1999). No differences were observed between DA cells in the VTA and SNc, and thus data from these two groups were combined. Figure 3, $a$ and $b$, shows that LTD can be elicited in DA cells of the VTA and SNc using a protocol similar to that that was effective in the NAc $(n=9 ; 65 \pm 6 \%$ of baseline). Surprisingly, however, unlike the LTD in the NAc, this form of LTD was not blocked by high concentrations of D-APV $(50-100 \mu \mathrm{M}$; Fig. $3 c ; n=$ $13 ; 75 \pm 4 \%$ of baseline). To determine whether mGluR activation was required for triggering LTD in the VTA, we again applied $(S)$-MCPG $(0.5-1.5 \mathrm{~mm})$ or the cocktail of mGluR antagonists used in the NAc experiments (MCPG, MPEP, and CPPG) and found that LTD could still be elicited (MCPG alone experiments, Fig. $3 d ; n=6 ; 64 \pm 3 \%$ of baseline; MCPG, MPEP, and CPPG experiments, $n=3 ; 72 \pm 5 \%$ of baseline).

These results demonstrate that activation of NMDARs or mGluRs is not required for the generation of LTD in the VTA and $\mathrm{SNc}$ and raise the question whether this form of LTD is triggered presynaptically or postsynaptically. Because many forms of LTP and LTD require changes in postsynaptic calcium concentration (Malenka and Nicoll, 1993), we asked whether loading cells with the calcium chelator BAPTA $(10 \mathrm{~mm})$ affected LTD. Figure $4 a$ shows that BAPTA blocked the generation of LTD $(n=5 ; 105 \pm$ $9 \%$ of baseline), strongly suggesting that the induction of this form of LTD requires a postsynaptic rise in intracellular calcium. One possible source of this calcium is voltage-dependent calcium channels. To test this possibility we clamped cells at -70 to $-100 \mathrm{mV}$ during the pairing protocol that should block or strongly limit the activation of voltage-dependent channels. This manipulation significantly reduced or blocked the triggering of LTD (Fig. $4 b ; n=$ $10 ; 89 \pm 6 \%$ of baseline).

One puzzling feature of these results is that activating synaptic inputs while voltage-clamping cells at depolarized potentials should not result in the activation of voltage-dependent calcium channels if dendritic regions were under perfect voltage control during the LTD induction protocol. To test whether synaptic activation was in fact required for the triggering of LTD, we stopped afferent stimulation and held cells at $-40 \mathrm{mV}$ for $400 \mathrm{sec}$. This elicited a modest, but significant, LTD $(n=4 ; 83 \pm 5 \%$ of baseline; data not shown). In the context of the previous results, this finding suggests that during the depolarization the dendritic regions escaped the voltage clamp allowing some activation of voltagedependent conductances. Presumably, some degree of additional depolarization was elicited in response to synaptic activation. An identical conclusion was reached by Jones et al. (2000) who also found that activation of calcium channels with repetitive depolarizing pulses elicited LTD in the VTA.

Many neurons express L-type calcium channels in their postsynaptic membranes, and activation of these channels can generate LTD in hippocampal CA1 pyramidal cells (Cummings et al., 1996). However, in the VTA and SNc, application of the L-type calcium channel antagonist nifedipine $(60 \mu \mathrm{M})$ did not block LTD (Fig. $4 c$; $n=8 ; 67 \pm 6 \%$ of baseline). Another possible source of calcium is calcium-permeable AMPA receptors that also can mediate synaptic plasticity at excitatory synapses (Mahanty and Sah, 1998; Laezza et al., 1999). EPSCs mediated by such calcium-permeable AMPA receptors display several characteristic traits including block by polyamines and inward rectification (Hollmann et al., 1991; Washburn et al., 1997). Such AMPA receptors, however, are unlikely to account for the triggering of LTD in the VTA and SNc because application of the polyamine NHPP-SP $(10 \mu \mathrm{M})$, which has been shown to reduce currents through calcium-permeable AMPA receptors (Washburn et al., 1997), had no significant effect on the EPSCs recorded in the VTA and SNc (Fig. $4 d ; n=4$ ).

The results thus far are consistent with the hypothesis that activation of non-L-type calcium channels is required for the induction of this form of LTD. Such high-threshold channels are found on midbrain DA cells (Cardozo and Bean, 1995), but antagonists of these channels cannot be used to test their role in LTD because these antagonists affect transmitter release (Luebke et al., 1993; Wheeler et al., 1994). DA, on the other hand, inhibits $\mathrm{N}$ - and $\mathrm{P} / \mathrm{Q}$-type calcium currents in midbrain DA cells (Cardozo and Bean, 1995) but has minimal effects on basal synaptic transmission (Jones and Kauer, 1999). Therefore, if one or more of these subtypes of calcium channels are required for generating LTD, DA might also inhibit the induction of LTD. In agreement with this prediction, DA [60 $\mu \mathrm{M}$; in the presence of the serotonin receptor antagonist methiothepin $(3 \mu \mathrm{M})$ ] (Jones and Kauer, 1999) blocked the induction of LTD (Fig. $5 a ; n=9 ; 106 \pm 7 \%$ of baseline). 
a

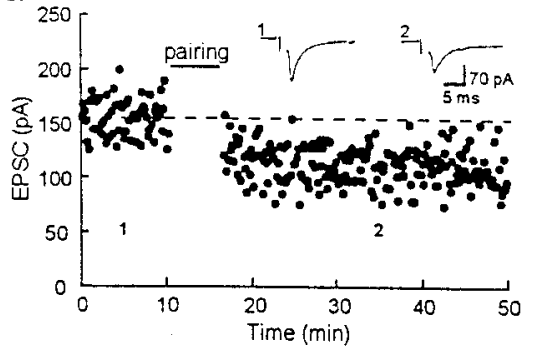

Figure 3. LTD can be elicited in the VTA and SNc and does not require activation of NMDA receptors or metabotropic glutamate receptors. $a$, Typical example of LTD induced by applying $1 \mathrm{~Hz}$ afferent stimulation while holding the cell at $-40 \mathrm{mV}$ ( pairing). Insets, EPSCs $(n=6)$ collected at the times indicated by the numbers $(1,2)$ on the graph. $b$, Summary graph of the average LTD elicited in nine VTA and SNc cells. $c$, Summary graph showing the lack of effect of applying D-APV $(50-100 \mu \mathrm{M})$ during the pairing protocol $(n=$ $13)$. $d$, Summary graph showing the lack of effect of applying $(S)$-MCPG $(0.5-1.5 \mathrm{mM})$ during the pairing protocol $(n=6)$.
C

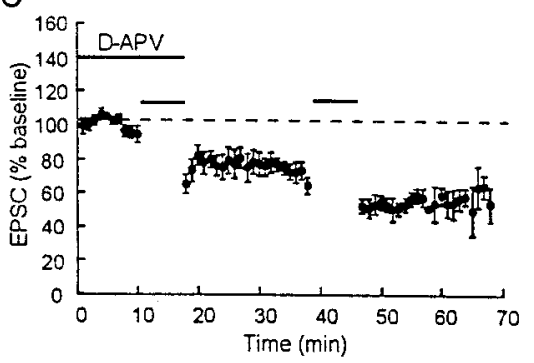

$\mathrm{b}$

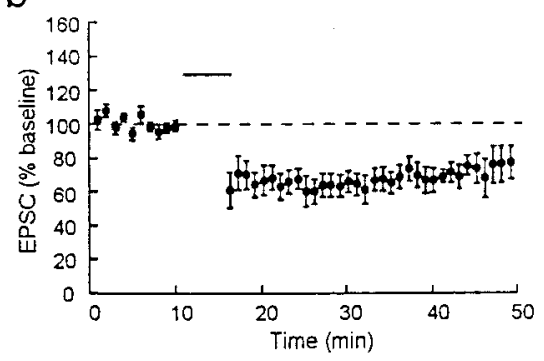

d

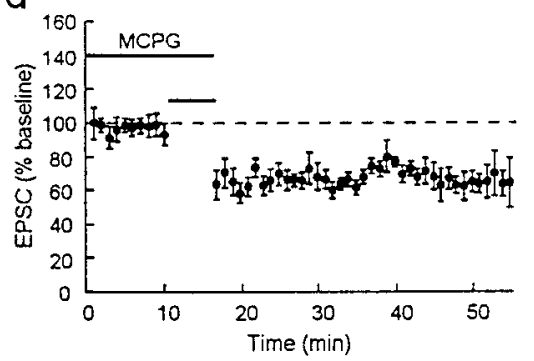

The inhibition of calcium currents by DA in these cells is mimicked by quinpirole, indicating that it is mediated by D2-like receptors (Cardozo and Bean, 1995). To determine the subtype of DA receptor responsible for the block of LTD, we compared the effects of the D1-like receptor agonist SKF $81297(10 \mu \mathrm{M})$ and quinpirole $(10 \mu \mathrm{M})$. SKF 81297 had no effect on the induction of LTD (Fig. $5 b ; n=4 ; 64 \pm 8 \%$ of baseline), whereas quinpirole prevented the triggering of LTD (Fig. $5 c ; n=11 ; 91 \pm 6 \%$ of baseline), demonstrating that like the inhibition of calcium currents, the block of LTD by dopamine is caused by activation of D2-like receptors. Finally, we also examined whether activation of DA receptors by endogenous DA influenced the generation of LTD by applying the D1-like receptor antagonist SCH-23390 $(10 \mu \mathrm{M})$ and the D2-like receptor antagonist eticlopride $(1 \mu \mathrm{M})$. Figure $5 d$ shows that blockade of DA receptors using these antagonists did not affect LTD $(n=6 ; 64 \pm 7 \%$ of baseline).

\section{DISCUSSION}

We have demonstrated that excitatory synapses on medium spiny neurons in the NAc and DA cells in the VTA and SNc can express LTD in response to synaptic activation during modest depolariza- tion. Taken with the previous demonstrations of LTP in these structures (Pennartz et al., 1993; Kombian and Malenka, 1994; Bonci and Malenka, 1999; Overton et al., 1999), these results indicate that activity can exert bidirectional control of synaptic strength at these synaptic connections. However, the underlying mechanisms of these forms of LTD and their modulation by DA differ significantly. LTD in the NAc requires NMDAR activation and is not affected by DA. Furthermore, it does not require activation of mGluRs or DA receptors, clearly distinguishing it from the LTD that has been observed in the dorsal striatum (Calabresi et al., 1992). In contrast, LTD in midbrain DA cells does not require activation of NMDARs but instead appears to be triggered by activation of non-L-type voltage-dependent calcium channels. Consistent with this hypothesis is the finding that repetitive depolarization of VTA neurons to activate these calcium channels induces a form of LTD that occludes with the synaptically evoked LTD (Jones et al., 2000). Furthermore, activation of D2like receptors, which has been shown to inhibit calcium currents in these cells (Cardozo and Bean, 1995), blocks the induction of LTD. It is conceivable that activation of dendritic potassium channels by DA (Missale et al., 1998) might also contribute to the block of LTD
Figure 4. LTD in the VTA and $\mathrm{SNc}$ requires a rise in postsynaptic calcium that is not caused by L-type calcium channels or calcium-permeable AMPA receptors. $a$, Summary graph showing that loading cells with BAPTA $(10 \mathrm{~mm})$ by adding it to the patch solution prevents LTD $(n=5) . b$, Summary graph showing that voltage-clamping the cells at hyperpolarized membrane potentials during the $1 \mathrm{~Hz}$ afferent stimulation prevents LTD $(n=10)$. Insets, EPSCs $(n=6)$ taken from one of these experiments at the time points indicated by the numbers $(1,2)$ on the graph. $c$, Summary graph showing that the L-type calcium channel antagonist nifedipine $(60 \mu \mathrm{M})$ does not prevent LTD $(n=8)$. $d$, Summary graph showing that the polyamine NHPP-SP $(10 \mu \mathrm{M})$ does not reduce EPSCs, indicating that these synaptic currents are not mediated by calcium-permeable AMPA receptors. a
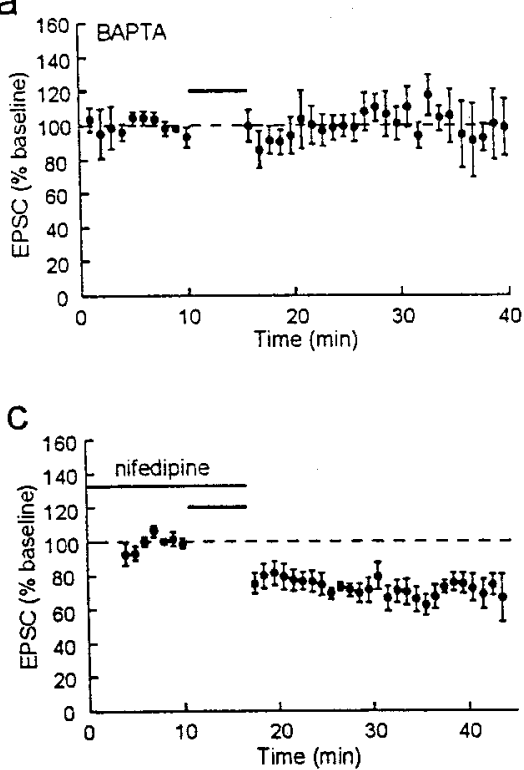

b

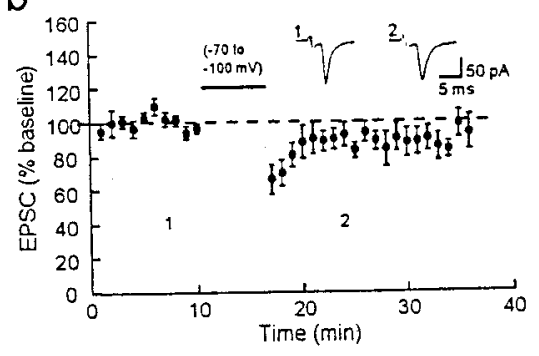

d

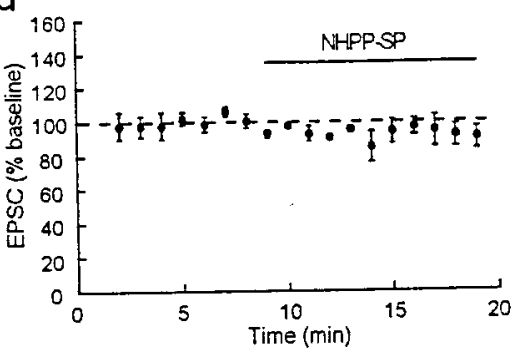



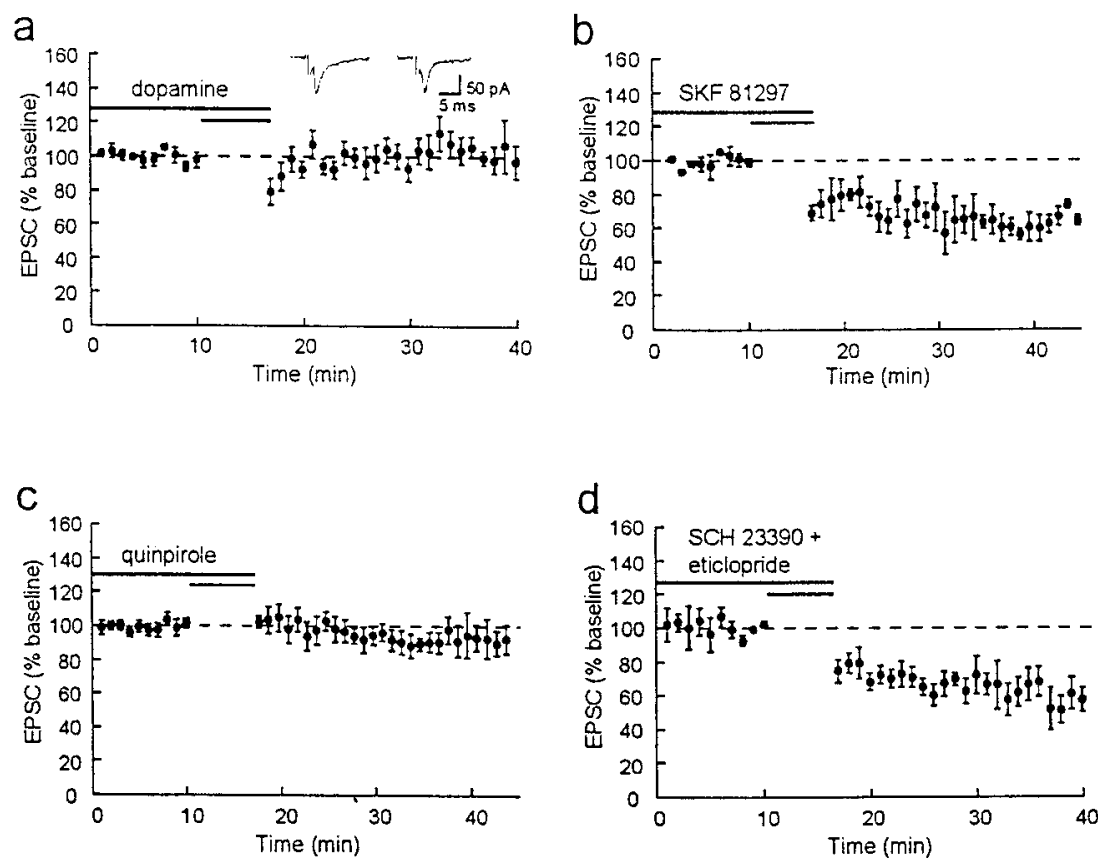

\begin{abstract}
Figure 5. DA prevents LTD in the VTA and SNc via activation of D2-like receptors. $a$, Summary graph showing that DA $[60 \mu \mathrm{M}$; in the presence of methiothepin (3 $\mu \mathrm{M})]$ prevents LTD $(n=9)$. Insets, EPSCs $(n=6)$ taken before and after the pairing protocol from one of these experiments. $b$, Summary graph showing that the D1 receptor agonist SKF $81297(10 \mu \mathrm{M})$ does not prevent LTD $(n=4)$. $c$, Summary graph showing that the D2 receptor agonist quinpirole $(10 \mu \mathrm{M})$ blocks LTD $(n=$ 11). $d$, Summary graph showing the lack of effect of D1-like (SCH-23390, $10 \mu \mathrm{M})$ and D2-like (eticlopride, 1 $\mu \mathrm{M})$ receptor antagonists on LTD $(n=6)$.
\end{abstract}

by DA. However, we think that this is unlikely because the wholecell pipette solution contained both cesium and TEA and we observed no change in holding current when DA was applied. Independent of the underlying mechanisms, this is the first evidence, to our knowledge, that DA acts as a modulator of excitatory synaptic input in the midbrain.

What might be the functional consequences of synaptic plasticity in these mesolimbic system structures? The NAc has long been suggested to play a key role as an interface between motivational and motor systems (Mogenson et al., 1980). More recently, extensive behavioral studies suggest that it plays a key role in several different types of Pavlovian and appetitive instrumental learning (see Robbins and Everitt, 1996; Kelley et al., 1997; Parkinson et al., 1999; Baldwin et al., 2000), some forms of which are dependent on NMDAR activation (Kelley et al., 1997; Baldwin et al., 2000). That excitatory synapses in the NAc express NMDAR-dependent LTD as well as LTP extends previous observations (Pennartz et al., 1993) and provides additional evidence that modification of synaptic weights at afferent inputs onto NAc cells may be an important mechanism that contributes to reward-related forms of learning.

The observation that repeated administration of psychostimulants decreases the spontaneous and evoked firing of NAc cells (Peoples et al., 1998; White and Kalivas, 1998) suggests that LTD may also be an important mediator of the adaptations in NAc circuitry that occur during the development of addiction. In terms of the effects of DA, theoretical work suggests that DA-mediated modulation of synaptic plasticity in areas that receive midbrain DA projections may be important for mediating changes in the representation of predictive reward signals (Montague et al., 1996; Schultz, 1998). Although we did not find any significant effect of DA on the triggering of LTD in the NAc, it is important to remember that the patterns of synaptic activity that elicit synaptic plasticity in vivo may be significantly different from those used in the reduced slice preparation, and thus further tests of the effects of DA on synaptic plasticity in the NAc are required.

That synaptic plasticity at the excitatory synapses between prefrontal cortical afferents and midbrain DA cells may be behaviorally important is supported by two lines of evidence. First, midbrain DA neurons alter their firing properties during learning in that they initially fire in response to a primary reward but, when this reward is predicted by a conditioned stimulus, the response of these neurons to the primary reward decreases while the response to the conditioned stimulus increases (Schultz et al., 1997; Schultz, 1998). Furthermore, if after learning the reward does not occur, the responses of the DA neurons decrease at the time the reward was expected. Because the major excitatory input to these cells comes from the prefrontal cortex, LTD at these synapses may importantly contribute to this change in the pattern of single-unit activity that is thought to serve as a predictor of reward (Schultz et al., 1997; Schultz, 1998). Second, there is evidence that psychostimulantinduced behavioral sensitization, a prominent model for some of the behavioral changes that occur during addiction (Kalivas and Stewart, 1991; Robinson and Berridge, 1993), involves NMDARdependent synaptic plasticity at these same synapses (Clark and Overton, 1998; Wolf, 1998; Cador et al., 1999). Previously, we and others demonstrated the existence of NMDAR-dependent LTP at these synapses (Bonci and Malenka, 1999; Overton et al., 1999). An additional role of LTD therefore would be to limit the synaptic drive onto midbrain DA cells and prevent the pathological overexcitation that may contribute to the development of addiction.

The inhibition of LTD by DA in the VTA and SNc also may have a physiological role. The dendrites of midbrain DA cells release DA that activates D2 autoreceptors leading to inhibition of their firing (Missale et al., 1998). The blockade of LTD by endogenous DA may counterbalance this inhibition and also provide a mechanism of spatially restricting the occurrence of this form of synaptic plasticity. Furthermore, blockade of LTD by DA would facilitate the generation of LTP that may be important for the changes in activity during learning mentioned above. Finally, many drugs of abuse either directly or indirectly cause the release of DA in the VTA and SNc (Koob and le Moal, 1997; Nestler and Aghajanian, 1997; Wise, 1998). Indeed, the psychostimulant amphetamine blocks LTD (Jones et al., 2000), suggesting that the inhibition of LTD may be an important event in the initial triggering of the neural adaptations that mediate addiction. Further work on the mechanisms of synaptic plasticity in the NAc and the VTA and SNc should help elucidate the role of these structures in a variety of forms of normal, adaptive learning and also contribute to our understanding of the neural mechanisms of addiction.

\section{REFERENCES}

Baldwin AE, Holahan MR, Sadeghian K, Kelley AE (2000) $N$-Methyl-Daspartate receptor-dependent plasticity within a distributed corticostriatal network mediates appetitive instrumental learning. Behav Neurosci 114:84-98.

Bear MF (1999) Homosynaptic long-term depression: a mechanism for memory? Proc Natl Acad Sci USA 96:9457-9458.

Bear MF, Abraham WC (1996) Long-term depression in hippocampus. Annu Rev Neurosci 19:437-462. 
Bonci A, Malenka RC (1999) Properties and plasticity of excitatory synapses on dopaminergic and GABAergic cells in the ventral tegmental area. J Neurosci 19:3723-3730.

Brabet I, Mary S, Bockaert J, Pin J-P (1995) Phenylglycine derivatives discriminate between mGluR1- and mGluR5-mediated responses. Neuropharmacology 34:895-903.

Cador M, Bjijou Y, Cailhol S, Stinus L (1999) D-Amphetamine induced behavioral sensitization: implication of a glutamatergic medial prefrontal cortex-ventral tegmental area innervation. Neuroscience 94:705-721.

Calabresi P, Maj R, Pisani A, Mercuri NB, Bernardi G (1992) Long-term synaptic depression in the striatum: physiological and pharmacological characterization. J Neurosci 12:4224-4233.

Cardozo DL, Bean BP (1995) Voltage-dependent calcium channels in rat midbrain dopamine neurons: modulation by dopamine and GABAB receptors. J Neurophysiol 74:1137-1148.

Clark D, Overton PG (1998) Alterations in excitatory amino acidmediated regulation of midbrain dopaminergic neurones induced by chronic psychostimulant administration and stress: relevance to behavioural sensitization and drug addiction. Addict Biol 3:109-135.

Cummings JA, Mulkey RM, Nicoll RA, Malenka RC (1996) $\mathrm{Ca}^{2+}$ signaling requirements for long-term depression in the hippocampus. Neuron 16:825-833

Hollmann M, Hartley M, Heinemann S (1991) $\mathrm{Ca}^{2+}$ permeability of KAAMPA-gated glutamate receptor channels depends on subunit composition. Science 252:851-853.

Huber KM, Sawtell NB, Bear MF (1998) Effects of the metabotropic glutamate receptor antagonist MCPG on phosphoinositide turnover and synaptic plasticity in visual cortex. J Neurosci 18:1-9.

Johnson SW, North RA (1992) Two types of neurone in the rat ventral tegmental area and their synaptic inputs. J Physiol (Lond) 450:455-468.

Jones S, Kauer JA (1999) Amphetamine depresses excitatory synaptic transmission via serotonin receptors in the ventral tegmental area. J Neurosci 19:9780-9787.

Jones S, Kornblum JL, Kauer JA (2000) Amphetamine blocks long-term synaptic depression in the ventral tegmental area. J Neurosci 20:5575-5580.

Kalivas PW, Stewart J (1991) Dopamine transmission in the initiation and expression of drug- and stress-induced sensitization of motor activity. Brain Res Rev 16:223-244.

Katz LC, Shatz CJ (1996) Synaptic activity and the construction of cortical circuits. Science 274:1133-1138.

Kelley AE, Smith-Roe SL, Holahan MR (1997) Response-reinforcement learning is dependent on $N$-methyl-D-aspartate receptor activation in the nucleus accumbens core. Proc Natl Acad Sci USA 94:12174-12179.

Kombian SB, Malenka RC (1994) Simultaneous LTP of non-NMDA- and LTD of NMDA-receptor-mediated responses in the nucleus accumbens. Nature 17:242-246.

Koob G, le Moal M (1997) Drug abuse: hedonic homeostatic dysregulation. Science 278:52-58.

Laezza F, Doherty JJ, Dingledine R (1999) Long-term depression in hippocampal interneurons: joint requirement for pre- and postsynaptic events. Science 285:1411-1414.

Luebke JI, Dunlap K, Turner TJ (1993) Multiple calcium channel types control glutamatergic synaptic transmission in the hippocampus. Neuron 11:895-902.

Mahanty NK, Sah P (1998) Calcium-permeable AMPA receptors mediate long-term potentiation in interneurons in the amygdala. Nature 394:683-687.

Malenka RC, Nicoll RA (1993) NMDA receptor-dependent synaptic plasticity: multiple forms and mechanisms. Trends Neurosci 16:521-527.

Missale C, Nash SR, Robinson SW, Jaber M, Caron MG (1998) Dopamine receptors: from structure to function. Physiol Rev 78:189-225.

Montague PR, Dayan P, Sejnowski TJ (1996) A framework for mesencephalic dopamine systems based on predictive Hebbian learning. J Neurosci 16:1936-1947.
Mogenson GJ, Jones DL, Yim CY (1980) From motivation to action: functional interface between the limbic system and the motor system. Prog Neurobiol 14:69-97.

Nestler EJ, Aghajanian GK (1997) Molecular and cellular basis of addiction. Science 278:58-63.

Nicola SM, Malenka RC (1997) Dopamine depresses excitatory and inhibitory synaptic transmission via distinct mechanisms in the nucleus accumbens. J Neurosci 17:5697-5710.

Nicola SM, Malenka RC (1998) Modulation of synaptic transmission by dopamine and norepinephrine in ventral but not dorsal striatum. J Neurophysiol 79:1768-1776.

Nicola SM, Kombian SB, Malenka RC (1996) Psychostimulants depress excitatory synaptic transmission in the nucleus accumbens via presynaptic D1-like dopamine receptors. J Neurosci 16:1591-1604.

Oliet SHR, Malenka RC, Nicoll RA (1997) Two distinct forms of longterm depression coexist in CA1 hippocampal pyramidal cells. Neuron 18:969-982.

Overton PG, Richards CD, Berry MS, Clark D (1999) Long-term potentiation at excitatory amino acid synapses on midbrain dopamine neurons. NeuroReport 10:221-226.

Parkinson JA, Olmstead MC, Burns LH, Robbins TW, Everitt BJ (1999) Dissociation in effects of lesions of the nucleus accumbens core and shell on appetitive Pavlovian approach behavior and the potentiation of conditioned reinforcement and locomotor activity by D-amphetamine. J Neurosci 19:2401-2411.

Pennartz CMA, Ameerun RF, Groenewegen HJ, Lopes da Silva FH (1993) Synaptic plasticity in an in vitro slice preparation of the rat nucleus accumbens. Eur J Neurosci 5:107-117.

Peoples LL, Uzwiak AJ, Guyette FX, West MO (1998) Tonic inhibition of single nucleus accumbens neurons in the rat: a predominant but not exclusive firing pattern induced by cocaine self-administration sessions. Neuroscience 86:13-22.

Robbins TW, Everitt BJ (1996) Neurobehavioral mechanisms of reward and motivation. Curr Opin Neurobiol 6:228-236.

Robinson TE, Becker JB (1986) Enduring changes in brain and behavior produced by chronic amphetamine administration: a review and evaluation of animal models of amphetamine psychosis. Brain Res Rev 396:157-198.

Robinson TE, Berridge KC (1993) The neural basis of drug craving: an incentive-sensitization theory of addiction. Brain Res Rev 18:247-291.

Schoepp DD, Jane DE, Monn JA (1999) Pharmacological agents acting at subtypes of metabotropic glutamate receptors. Neuropharmacology 38:1431-1476.

Schultz W (1998) Predictive reward signal of dopamine neurons. J Neurophysiol 80:1-27.

Schultz W, Dayan P, Montague PR (1997) A neural substrate of prediction and reward. Science 275:1593-1599.

Segal DS, Schuckit MA (1983) Animal models of stimulant-induced psychosis. In: Stimulants: neurochemical and clinical perspectives (Creese I, ed), pp 131-167. New York: Raven.

Sejnowski TJ (1977) Storing covariance with nonlinearly interacting neurons. J Math Biol 4:303-321.

Singer W (1995) Development and plasticity of cortical processing architectures. Science 270:758-764.

Washburn MS, Numberger M, Zhang S, Dingledine R (1997) Differential dependence on GluR2 expression of three characteristic features of AMPA receptors. J Neurosci 17:9393-9406.

Wheeler DB, Randall A, Tsien RW (1994) Roles of N-type and Q-type $\mathrm{Ca} 2+$ channels in supporting hippocampal synaptic transmission. Science 264:107-111.

White FJ, Kalivas PW (1998) Neuroadaptations involved in amphetamine and cocaine addiction. Drug Alcohol Depend 51:141-153.

Wise RA (1998) Drug-activation of brain reward pathways. Drug Alcohol Depend 51:13-22.

Wolf M (1998) The role of excitatory amino acids in behavioral sensitization to psychomotor stimulants. Prog Neurobiol 54:679-720. 